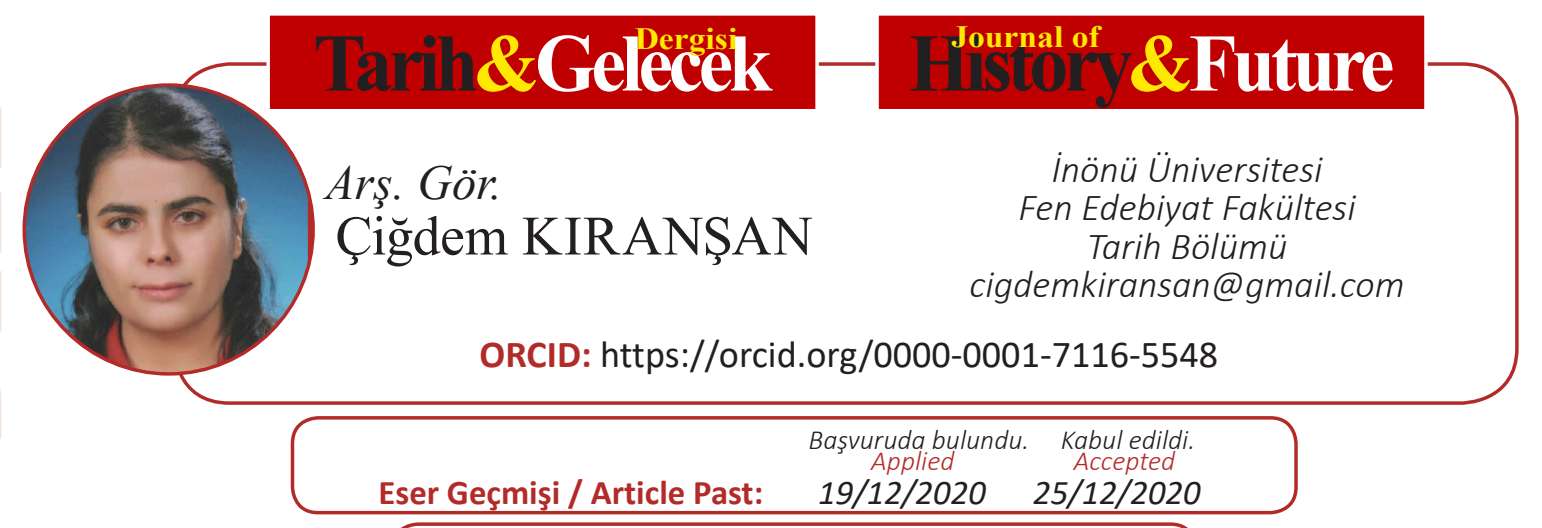

Araştırma Makalesi

DOI: http://dx.doi.org/10.21551/jhf.843346

Research Paper

Orjinal Makale / Orginal Paper

\title{
Hindistan İstiklal Mücadelesinin Kahramanlarından Bal Gangadhar Tilak'1n Hayatı ve İcraatları
}

\author{
The Life and Activities of Bal Gangadhar Tilak, one of the Heroes of \\ Indian Intelligence Struggle
}

"Swaraj benim doğuştan hakkımdır ve ben de ona sahip olacă̆ım."

Bal Gangadhar Tilak

$\ddot{O} z$

XVIII. yüzyılın son çeyreğinden itibaren Hint alt kıtasına tamamen hâkim olan İngiliz yönetimine karşı pasif direniş, Hint alt kıtasının bağımsızlık sürecinde en etkili mücadele yöntemi olmuştur. Siyasî bir ifade biçimi olan bu anlayışta vergi ödememe, mahkemelere karşı grev, okul, sivil ve askerî düzenlemeleri reddetmek, yabancı malları boykot, milli bağımsızlı isteğini her firsatta dile getirme gibi eylemler yer almaktadır. Milliyetçilik idealini benimseyen Hint liderleri, diğer bazı toplumlarda gördüğümüz Batı hayranı elitlerin aksine, kendi öz geleneklerine bağlı kalmış ve daha özgün tavır sergilemişlerdir. Bu liderler, şiddetsiz siyasal sistem ve eylemleri sayesinde emperyalist egemenlik arzusu ile insanlık dışı uygulamalara başvurmaktan çekinmeyen İngilizlerin bu arzularını yavaş yavaş zayıflatılmış ve nihayetinde İngiliz sömürgeciliğini yıkmayı başarmıştır. Böylece adaletsizliğe başkaldırının şiddet ve kanla değil de fikirsel ve barışçıl eylemlerle zafer kazanacağına tüm dünya şahit olmuştur. Hint alt kıtasının istiklal mücadelesi kahramanlarından Bal Gangadhar Tilak'ın hayatı ve swaraj; yani ulusal egemenlik için vermiş olduğu mücadelesi bu makalenin esas konusunu teşkil edecektir.

Anahtar Kelimeler: Hint alt kıtası, pasif direniş, swaraj, swadeshi, Bal Gangadhar Tilak 


\begin{abstract}
From the second half of the 18th century, passive resistance against British rule, which completely dominated the Indian subcontinent, has been the most effective method of struggle in the independence process of the Indian subcontinent. This understanding, which is a form of political expression, includes actions such as not paying taxes, strikes against courts, rejecting school, civil and military regulations, boycotting foreign goods, and expressing the desire for national independence at every opportunity. These leaders, thanks to their nonviolent political system and actions, gradually weakened these aspirations of the British, who did not hesitate to resort to inhumane practices with the desire for imperialist domination and eventually managed to overthrow British colonialism. Thus, the whole world has witnessed that the revolt against injustice will triumph not with violence and blood but through intellectual and peaceful actions. Hind leaders, who embraced the ideal of nationalism, adhered to their own traditions and adopted a more original attitude, unlike the Western-fan elites we see in some other societies. The life and swaraj of Bal Gangadhar Tilak, one of the heroes of the struggle for independence of the Indian subcontinent; In other words, his struggle for national sovereignty will constitute the main subject of this article.
\end{abstract}

Keywords: Indian sub-continent, passive resistance, swaraj, swadeshi, Bal Gangadhar.

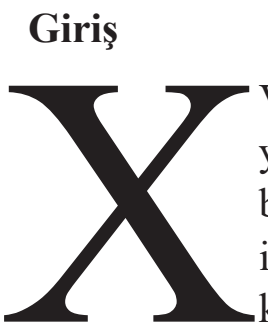

VIII. yüzyılın son çeyreğinden itibaren Hint alt kıtasına tamamen hâkim olma yolunda önemli adımlar atan İngiltere, 1857 Tımarlı Sipahi kalkışmasıyla bu emeline ulaşma yolunda kritik bir fırsatı ele geçirmiştir. Nitekim bu ilk isyanın başarısızlıkla sonuçlanması Hint alt kıtasında tamamen İngilizlerin kontrolünde olan yeni bir yönetim yapısı ve politik anlayışın gelişmesine yol açmıştır. ${ }^{1}$ Sanayi inkılabının gerçekleşmesiyle de Hindistan tamamen İngilizlerin pazarı haline geldi. Buhar gücü yalnızca teknolojik üstünlüğü sağlamakla kalmamış aynı zamanda İngiltere ile Hindistan arasındaki yolu da kısaltarak Hindistan'ın pamuk ve ipliğini kısa bir süre içerisinde İngiltere'de işleyerek yeniden yüksek fiyatlarla Hint pazarına döndürme imkânı sağlamıştı. İngilizler, buradaki yerli üretimi sekteye uğratıp on binlerce kişiyi de işsiz bırakmıştı. Tüm bu gelişmeler Hint pazarında tahribata neden olmuştu. ${ }^{2}$ Bununla birlikte toplumsal yapılar, siyasi ilişkiler, hukuk anlayışı gibi hususlar İngiliz sistemi öğeleriyle değişmekteydi. Aynı zamanda bu yayılma politikası çerçevesinde nizamlık ve racaların topraklarını ilhakı ve eski düzenin kurumlarının yıkılması bazı hoşnutsuzlukları da beraberinde getirmiştir. ${ }^{3}$

1 K.Henry George,British Administration During The Revolt of 1857, New Delhi 1985; Arthur D. Innes, A Short History of The British in India, New Delhi 1985.; R. Dutt, The Economic History of India in the Victorian Age (from the Accession of Queen Victoria in 1837 to the Commencement of the Twentieth Century), London 1958. D. Kincaid, British Social Life in India 1608-1937, London 1939, s.130vd.

2 Geniş bilgi için bkz. R.W. Frazer, A Story of the Nations British India, London 1918; H.George Briggs, The Nizam His History and Relations with the British Government I-II, Delhi 1985

3 Kemal H. Karpat, İslam'ın Siyasallaşması, (nşr. Şiar Yalçın), İstanbul 2013, s. 1; A. R. Desa1, Social Bankround of India Nationalism, Bombay 1966, s.16 vd.. H. George Briggs, The Nizam His History 
Nitekim İngilizler, kalıcı bir hâkimiyet için eğitim alanında yenilikler gerçekleştirmeyi de ihmal etmemişlerdi. Yerli edebiyat canlandırılmış ve yerli bilginler teşvik edilmişş olsa da bunun Hindistan'daki müstakbel İngiliz yönetimi açısından olumsuz sonuçlar doğurabileceği anlaşıldı. Nitekim İngiliz eğitim sistemi Avrupa edebi bilgilerine sahip olmasına rağmen eski gelenek, düşünce ve anlayış tarzlarına bağlı bir yerli sınıfın doğmasını böylece ilerde İngilizlerle yapılacak mücadelenin önderleri olmalarını sağladı. ${ }^{5}$ Neticede liderler XIX. ve XX. yüzyıl boyunca bu değerleri silah yerine kullanıp, İngiliz hâkimiyeti altındaki Hindistan'da iktidara mütemadiyen el koymuşlardır. ${ }^{6}$ Milliyetçilik idealini benimseyen Hind liderleri, diğer bazı toplumlarda gördüğümüz Batı hayranı elitlerin aksine, daha özgün tavır sergilemişlerdir. Bu liderler, kendi öz geleneklerine bağlı kalmış, hatta bu bağllık sonraları aşırı milliyetçiliğe dönüşmüştür. ${ }^{7}$

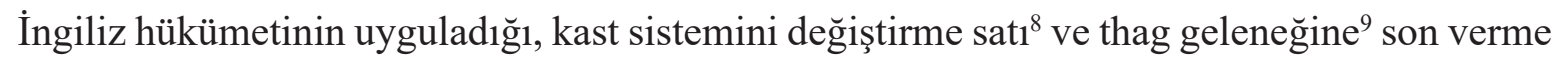
gibi olumsuz politikalar bölgedeki önde gelen Hint liderleri, Hint kimliğini korumanın yanı sıra dini, sosyal ve iktisadi hayata yön verme konusunda da faaliyete geçmeye sevk etmiştir. Buna bağl1 olarak gelişen fikrî hareketlilik neticesinde Hint ahalisi çeşitli görüşler ve bu görüşler çerçevesinde oluşan ekoller doğrultusunda ihya sürecine girmiştir. Arya Samaj, Brahmo Samaj gibi Hint dinini

\section{and Relations with the British Government I-II, Delhi 1985}

1813 Hindistan kanununda "yerli edebiyatı canlandırıp, yerli bilginleri teşvik etmek için şirkete yılda 100.000 rupi ayrılacağı ve açılacak yüksekokullar üzerinde Londra'daki Denetleme Kurulu'nun söz sahibi olacağı” vurgulanmıştır. S. Vural, Hindistan’da İngiliz Yönetimi, Malatya 2006, s.13, (Basılmamış Doktora Tezi)

5 Bkz. Y.H. Bayur, Hindistan Tarihi III, Ankara 1987, s.292 vd.

6 A. J. Toynbee, Dünya ve Garp, (nşr. E.Bilgiç), s.53 vd.

7 Aziz Ahmed, Hindistan'da İslam Kültürü Çalışmaları, (nşr. L. Boyacı), İstanbul 1995, s.365 vd; Hunter W.W., The Indian Musalmans, London 1871, s.34

8 Sanskritçede “iffetli, namuslu kadın” anlamına gelen “satı”, Kuzey Hindistan'daki Raçputlar başta olmak üzere ülkedeki bütün Hindular arasında büyük saygı duyulan bir gelenekti. Satı, bir kadının kocasının cenaze töreninde kendini ateşe atarak hayatına son verme geleneği olup ateşe atlayarak kendini kocası uğruna öldüren kadın erdemli kadın olarak değerlendirilir ve doğrudan cennete gittiğine inanılırdı. Bu sebeple kendini satı olarak adayan kadına Tanrıça olarak bakılır ve onun hatırasına tapınaklar inşa ettirilirdi. Satı geleneği hakkında geniş bilgi için bkz., A. Zahid Khan, "Socio-Economic Reforms”, Road to Pakistan, (nşr. H.Msaid-S.Mujahid-A.Zahid Khan), Karachi 1990, s.234; E. W. Hopkins, "The Growth of Law and Legal Instituons”, The Cambridge History of India I, (nşr.E.J. Rapson), Delhi 1955 s.259 vd; H. V .Lovett, “The Growth of Educational Policy, 1858-1918”, The Cambridge History of India VI, (nşr. H. H. Dodwell), Delhi1958, s.341; P. Woodruff, The Men Who Ruled India I, New York 1964, s.253 $\mathrm{vd}$.

9 Orjinali sanskriçe "sthaga" olan ve "şiddet suçluları" anlamına gelen bu kelime Hinducada "thag" şeklinde telaffuz edilmekte olup hırsızlık veya kötülük yapan thag mensupları seyahat eden veya eğlenen bir grubun içine katılırlar ve burada ele geçirdikleri insanları boğarak öldürerek değerli eşyalarına da el koyarlardı. Thaglar ele geçirdikleri bu değerli eşyaları kendilerine ayırırken öldürdükleri kişilerin cesetlerini de kötülük tanrıçaları Kali’ye adarlardı. O dönemde thagların asla İngiliz seyyahlara saldırmadıkları bilindiği halde Hindistan İngiliz Hükümeti bunları ortadan kaldırmaya karar vermiş ve 1830'da üç binin üzerinde thag, Albay William Sleeman tarafından ele geçirilmiş ve bunların 412'si idam edilirken geriye kalanı da hapsedilerek bu tehlike ortadan kaldırılmıştır. Thag mezhebinin bu faaliyetleri 1890'lara gelindiğinde tamamen ortadan kaldırılmışsa da suçla ilgili durumları ifade etmek maksadıyla thag terimi hala kullanılmaktadır. Geniş bilgi için bkz.; H. Beveridge IV, s.190 vd.; İkramuddin Qidwai, "The Establishment of the British Raj”, Road to Pakistan, (nşr. H.Msaid-S.Mujahid-A.Zahid Khan), Karachi 1990, s.509; A. Zahid Khan, "Socio-Economic Reforms", Road to Pakistan, (nşr. H.Msaid-S. Mujahid-A.Zahid Khan), Karachi 1990, s.234; H.G.Rawlinson, A. Concise History of the Indian People, Oxford 1958, s.310. 
reforme eden ekoller Hindistan'ın istikbalinde önemli bir yer teşkil ederken gelecek kuşaklara da ilham kaynağı olmuştur. Ekollerin sloganı olan "Vedalara dönüşs", Hinduizm’i yeniden yapılandırmak ve reforme etmek için Hinduların milli gururunu ve bilincini tutuşturmak diğer bir deyişle milli birliğe gerçek yönelişi sağlamayı esas edinmiştir.

Nitekim Hint alt kıtasının önde gelen liderleri gelenek göreneklerine sıkı bağlı oldukları gibi İngiliz yönetimine karşı mücadele politikası olarak Pasif direnişi tercih etmiştir. Pasif direniş kavramı özgürlük ve adalet merkezinde insanın vicdani duyguları ile hareket etmesi gerektiğini ve adalet için mücadele etmeyi amaçlamakta olup bu mücadelede şiddet ve kuvvet kullanımını reddetmektedir. Pasif direnişin Hint dilindeki karşılı̆̆ 1 ahimsa, satyagraha, swadeshi gibi çeşitli türleri ${ }^{10}$ mevcut olup önde gelen en önemli lideri Gandhi, Cayna dininin temel ilkesi olan ahimsay1 yani tüm canlılara saygı duyup onlara zarar vermeme ilkesini şiddet karşıtlığına dayanan bir mücadele yöntemine dönüştürmüştür. Daha sonra ahimsa ve sivil itaatsizlik öğretilerinden yola çıkarak "Satyagrahayı" oluşturdu. Hakikat/sat ve sebat/agraha kelimelerinden oluşan bu kavrama göre insan, inandığ1 gerçeği ilan etmelidir ve hiç kimseye karşı şiddet göstermeden bunun uğrunda ölmeye hazır olmalıdır. Satyagraha insanı iki ayrı alanda mücadele etmeye çağırır: Birinci alan; dış dünyadır. İnsanı dış dünyaya karşı sivil itaatsizlik, pasif direniş ve şiddet aleyhtarlığı ilkelerine sadık kalma inancıyla savunmaktadır. İkinci alan ise insanın kendi benliğidir. İnsan nefis terbiyesi, riyazet ve oruç gibi yöntemlerle nefsini arındırıp ruhunu dünyevi arzulardan kurtarmalıdır. Gandhi, toplumsal ve siyasal hedeflere ulaşma felsefesinin adını "Satyagraha" olarak belirlemiştir." Swadeshi yabancı ürünleri boykot anlamına gelmekte olup ${ }^{12}$ Swaraj ise yabancı hâkimiyetinden kurtulma, kendi kendini yönetme yani ulusal egemenlik anlamına gelmektedir. ${ }^{13}$

Hint alt kıtasında sömürgeci güçlere karşı en etkili mücadele yolu olan Swaraj'ın ilk ve en güçlü savunucularından biri olan Bal Gangadhar Tilak (23 Temmuz 1856-1 Ağustos 1920) ${ }^{14}$, Hint alt kıtasında İngiliz yönetimine son veren baş aktörlerden biri olarak gösterilmektedir. Milliyetçi, gazeteci, öğretmen, sosyal reformcu, avukat ve bağımsızlık eylemcisi olarak öne çıkmaktadır. ${ }^{15}$ Tilak, Swaraj'ın asil hedefine ulaşmak için Swađeshi, boykot, ulusal eğitim ve pasif direniş gibi

10 Sivil itaatsizlik hakkında geniş bilgi için bkz.; Anıl Samarth, Shivaji and the Indian National Movement, Somarya Publications Pvt., Bombay 1975.; Jürgen Habermas, Sivil İtaatsizlik, (nşr. Hayrettin Ökçesiz), Afa Yayınları, İstanbul 1995,s.7-22.; Şeniz Anbarlı, “Bir Pasif Direnme Modeli Olarak Sivil İtaatsizlik”, Cumhuriyet Üniversitesi, İktisadi ve İdari Bilimler Fakültesi Dergisi II/1, 2001, s.319-328.

11 Henry David Thoreau, Sivil ve İtaatsiz, (nşr. Emine Ebru),Kafekültür Yayıncılık, İstanbul 2014, s. 214.

12 Anıl Samarth, Shivaji and the Indian National Movement, Somarya Publications Pvt., Bombay 1975, s.6vd.

13 Sanskrit dilinde sva:öz ve racya:yönetim anlamına gelmektedir. Yani “bağımsızlık” anlamına gelmektedir. Geniş bilgi için bkz. N. Pandey, The İndian Nationalist Movement 1885-1947, New Delhi 1979, s. 51vd; B. Pattabhi Sitaramayya, Gandhi and Gandhizm I., Allahabad 1943; Raghavan N. Iyer, The Moral and Political thought of Mahatma Gandhi, New Delhi 2003,s.346vd.;H. Kulke- D. Rothermund, Hindistan Tarihi, ( nşr., M. Günay), İstanbul 2001, s.405; Bipan Chandra, India's Struggle for İndependence, s.184; Micheal Nicholsan, s.30.; R.C. Majumdar, British Paramountcy and İndian Renaissance I., Bombay 1988.

14 Tilak hakkında geniş bilgi için bkz. S.S. Angadi, Bal Gangadhar Tilak: A Study of His Role in the Indian Nationalist Movement, Karnatak University, Dharwad 1992.; Babu Aurobindo Ghose, Bal Gangadhar Tilak His Writings and Speeches, Ganesh, Madras 1922.; Selected Documents of Lokamanya Bal Gangadhar Tilak 1880-1920 I-IV., (Ed. Ravindar Kumar), Anmol Publications, 1992. 
teknikleri uygulamıştır.

Halk arasında Lokamanya olarak adlandırılan asıl adı Kesav Gangadhar Tilak, Maratha eyaletinde (Batı Dekkan bölgesi) orta sınıf bir Brahman ailede doğdu. ${ }^{16}$ Babası Gangadhar Pant, öğretmen ve Sanskritçe uzmanı olarak bilinen bir bilgindi. ${ }^{17}$ Babasının Poona'ya tayin edilmesi onun eğitim almasi için bir firsat oldu. ${ }^{18}$ Tilak, Poona'da Dekkan Kolejinde eğitim gördü ve 1877 yılında mezun oldu. Bu süreçte Sanskritçe, matematik, astronomi, felsefe ve edebiyat üzerine çalışmalar yaptı. ${ }^{19}$ Poona'da özel bir okulda matematik öğretmeye başladı ancak daha sonraki süreçte okuldaki meslektaşları ile ideolojik farklılıkları nedeniyle öğretimden çekilmeye karar verere ${ }^{20}$ Mahratta Gazetesinde yazmaya başlad $1 .{ }^{21}$ Tilak, istiklal yolunda verdiği mücadeleyi iç ve dış kamuya duyurmak amacıyla 1881 yılında çıkardığı Kesari Gazetesi haftalık olarak basılırken daha sonra söz konusu gazete, günlük olarak basılmaya başlamış olup günümüzde hala devam etmektedir. ${ }^{22}$

Hindistan yeni neslinin eğitim kalitesini daha fazla arttırmak ve bunu yaparken de Hindistan kültürünü bilen genç nesillerin yetişmesi amacı ile Deccan Education Society/Dekkan Eğitim Topluluğunu arkadaşları Gopal Ganesh Agarkar, Mahadev Ballal Namjoshi ve Vishnushastri Chiplunkar ile kurduktan sonra öğretmenlik yaptığ bir yüksekokula dönüştürdü. Bu eğitim kurumunda din ve kültürünün yeniden doğuşuna vurgu yapılmıştır. ${ }^{23} \mathrm{Bu}$ arada Bombay Üniversitesinde okuduğu hukuk bölümünden 1879 yılında mezun oldu. Üniversite eğitimi alan ilk nesil Hintlilerden biriydi. Tilak, mezuniyetinden kısa bir süre sonra döneminin sosyal ve politik sorunlarına ciddi bir ilgi duyarken İngilizler tarafından getirilen eğitim sistemi üzerine reformlar yapmak istemiștir. O sebeple Maratha'da eğitimi yaymak için

16 Lokamanya halkın sevgili lideri anlamına gelmektedir Çocukluktaki adı Keshav Rao'ydu. Balwantrao olarak da adlandırıldı. Sevgiyle Bal olarak anıldı. Vishnuchandra Sharma, s.3; S. S. Angadi, s.64

17 Böyle bir aile ortamında büyümek ona Sanskritçe sevgisini ve eski Hint dinine ve kültürüne sayg1 duymasını sağladı Üç kız kardeşi vardı. Tilak on yaşındayken annesi, on altı yaşında ise babası da vefat etti. Babası ölmeden önce onu 1871 yılında Tapi Bai ile evlendirdi. Düğün sırasında Tilak’a soruldu çeyizde ne istiyorsunuz - para, kıyafet ve süs eşyaları? O, sadece kitap istedi. Babası, geride ona çok az miktarda para bırakmıştı. Tilak bu meblağ ile kardeşlerinin eğitim masraflarını yönetmek zorunda kaldı. Geniş bilgi için bkz; Joseph Baptısta, About Lokamanya Tilak, Vavilla Press, Madras 1922,s. Ivd.; Babu Aurobindo Ghose, Bal Gangadhar Tilak his Writing and Speeches, Madras 1922;

18 Jai Narain Sharma, The Political Thought of Lokamanya Bal Gangadhar Tilak XXIV,Concept Publishing Company,New Dehli 2009, s. 13.

19 Üniversitenin ilk yıllarında vücut geliştirmeye yönelik egzersizler yaptı̆̆ı, güreş, yüzme, jimnastik alanında ilgisi olduğu gibi tam bir kitap kurdu olduğu, özellikle matematik alanındaki başarısı ile de dikkat çekmekteydi. Bkz. Vishnuchandra Sharma, Tilak the Torch Bearer of Swaraj, New Delhi 2018,s. 5.

20 Richard I. Cashman, The Myth od the Lokamanya Tilak and Mass Politics in Maharashtra, University of Calfornia Press, London 1975, s. 190vd.

21 Joseph Baptısta, About Lokamanya Tilak, Vavilla Press, Madras 1922,s. IXvd.; S.S. Angadi, s. 17. D.V. Tahmankar, Lokamanya Tilak, London 1956,s. 26,27.

22 Kesari gazetesi Tilak tarafından çıkarılmıştır. Marathi dilinde çıkarılmıştır. Tilak’ın siyasi düşüncelerini halka iletmede önemli bir araç olmuştur. Kesari gazetesi için bkz. Avanish Patil," Public Opinion in Colonial India: The Kesari and the Kolhapur Affair, 1881-1883", Proceedings of the Indian History Congress LXVII, 2006 s. 711-724https://www.jstor.org/stable/44147990 01.12.2020.

23 Joseph Baptista, About Lokamanya Tilak, Vavilla Press, Madras 1922,s. Vvd.; Dhananjay Keer, Lokamanya Tilak Father of our Freedom Struggle, Forthcoming Books, Bombay 1959,s.41. 
bir reformlar başlatırken özellikle kadın ve erkeklere özgü eğitim müfredatının olması gerektiğini vurgulamıştır. ${ }^{24}$

Esasen Tilak, İngilizler yardımıyla sosyal reform yapılmasından yana olmadığı için batıyı örnek alan toplumsal reformların bağımsızlık için siyasal mücadeleyi zayıflatacağı görüşündeydi. $\mathrm{Bu}$ nedenle erken yaşta evliliğe kişisel olarak karşı çıkmasına rağmen, 1890 yılında İngilizler tarafından Poona'da yapılan “Yaş Rızası Yasası”na karşı çıktı ve bunu Hinduizm'e müdahale ve tehlikeli bir emsal olarak gördü. Yasanın en belirgin özelliği bir kızın evlenebileceği yaşı 10'dan 12 ’ye çıkarmasıydı. Yasa temel olarak şu maddeleri içermekteydi.

* 12 yaşın altındaki bir kızla cinsel ilişki suç muamelesi görmeli

* Kız çocukları erken yaşta evlenirlerse olgunluğa ulaştıklarında boşanma hakkına sahip olmalı

* Reşit olmayan bir kızla evlenen erkeğin karısını onunla yaşamaya zorlama hakkı olmamalı

* Dul bir kadın yeniden evlendikten sonra ilk kocasından kalan mirasa sahip olabilmeliydi.

Tilak ve arkadaşları, bu yasaya aşağıda yer alan bazı yapıcı önerilerde bulunmuştur:

* Kızlar on altı yaşından önce evlenmemeli

* Erkekler ise yirmi yaşından önce evlenmemeli

* Eğer bir dul erkek yeniden evlenmek istiyorsa kırk yaşını doldurduktan sonra evlenmemeli

* Bir erkek ikinci kez evlenmek isterse sadece dul bir kadınla evlenmeli

* Alkol tüketimi tamamen yasaklanmalı

* Damat ve gelin satışı uygulaması (çeyiz sistemi) tamamen durdurulmalı

* Dulların sakal ve kılık kıyafet şekil bozukluğu giderilmeli

* Bu reformları kabul edenler gelirlerinin onda birini sosyal hizmete bağışlamalıdır. ${ }^{25}$ Ancak İngiliz yönetimi bu grubun önerileri dikkate almayınca Tilak, Kesari Gazetesinde Hindistan toplumunun köklü bir millet olduğunu bu nedenle reformların bir gecede çıkarılması yerine kademeli ve dikkatli bir şekilde yapılması gerektiğini vurgulamıştır. ${ }^{26}$

$1885^{\prime}$ te kurulan Hindistan Milli Kongresi /All India Congress ${ }^{27}$ ülkedeki gayrimüslim ahalinin önemli siyasi, iktisadi ve idari sorunlarını her yıl düzenli olarak yapılan toplantılarla gündeme taşıdığı gibi Hindistan'ın refahı ve ilerlemesi için kamuoyunu da yönlendirme icraatlarında bulunmuş olan bir partidir. ${ }^{28}$ Tilak, aynı zamanda Hindistan siyasi tarihinin şekillenmesinde önemli

24 Dhananjay Keer, ,s. 26-29.; T.V.Parvate, Bal Gangadhar Tilak a Narrative and İnterpretative Review of his Life, Career and Contemporary Events, Navajivan Publishing House, Ahmedabad 1958, s.41.

25 Dhananjay Keer, s.56-58; Vishnuchandra Sharma, Tilak the Torch Bearer of Swaraj, New Delhi 2018, s.14.

26 Jai Narain Sharma, The Political Thought of Lokamanya Bal Gangadhar Tilak XXIV,Concept Publishing Company, New Dehli 2009, s. 26-40.

27 Geniş bilgi için bkz. B. Pattabhi Sitaramayya, The History of the Indian National Congress ( 18851935) I., Bombay 1946; G. A. Natesan, The National Congress, Madras 1917; V. K. Agnıhotri, Indian History, New Delhi 2010, s. 382. 
rol alan bu Kongre Partisinin önde gelen temsilcilerinden olup Kongredeki 1lımlı tutumu ile de dikkat çekmektedir. ${ }^{29}$

Nitekim Tilak’1 Hint alt kıtasında ölümsüz kılan faaliyetlerinden biri de milliyetçilik hareketlerinin yaygınlaştırmak için düzenlemiş olduğu festivallerdir. 1893 yılında Ganesh ${ }^{30}$ ve 1895 yılında Shivaji ${ }^{31}$ olmak üzere iki önemli festival düzenledi. ${ }^{32}$ Tilak'ın da doğmuş olduğu eyalet olan Maratha, 1674-1818 yılları arasında varlığını sürdürmüş bir Hint devletidir. Marathalar, Shivaji önderliğinde XVII. yüzyılda önce Babürlü imparatorluğuna karşı daha sonra da İngiliz yönetimine karşı mücadele etmişlerdi. Tilak bu mücadele geleneğinden yararlanmak istemiştir. Mücadele lideri yani Maratha İmparatorluğunun kurucusu Shivaji Maharaj'ın doğum yıl dönümünü kutlamak için Shri Shivaji festivalini düzenledi. Ganesh ise Hinduizm'in tanrılarından fil başlı adına asırlardır düzenlenen bir festival olup hem çok eski, hem de evrenseldir. Aynı zamanda bu vesileyle tüm kastlar bir araya getirilmiş olup tüm Hinduları kucaklayan bir festivale haline dönüşmüştür. Tilak tarafından başlatılan ve her yıl binlerce kişinin katılımıyla gerçekleşen bu festivallerden birinde Tilak, Lokamanya unvanı ile onurlandırılmıştır. ${ }^{33}$ Aynı zamanda tüm kast ve topluluklardan sıradan insanların adeta bir buluşma yeri olarak hizmet eden bu festivaller zamanla dini ve sosyal açıdan işlevsel bir hal almıştır. Zaman içinde kültürel programlar ve milliyetçi konuşmalarla da bütünleştirilen bu festivaller tüm insanlara vatanseverlik duygusu aşılamıştır.

1897 y1lında iki rütbeli İngiliz askerinin Hintlilerce öldürülmesi üzerine Tilak cinayeti kışkırtmakla suçland1, on sekiz ay hapis cezasına çarptırılmıştır. ${ }^{34}$ Hapisten çıktıktan sonra "Swaraj benim doğuştan hakkımdır ve bende ona sahip olacă̆ım." sloganını benimserken ${ }^{35}$ ahali tarafından

73 yıl olmak üzere toplamda 135 yılını iktidarda geçirmiş sadece kısa bir dönem iktidarı muhalefet partisine kaptırmıştır. Partinin Hindistan siyasi hayatına etkisi hakkında bkz. Padmasha, Indian National Congress and the Muslims (1928-1947), New Delhi 1980, s.250; N.C. Saxena, Muslims and the India National Congress, Delhi 1955, s.52; R.C. Majumdar, Struggle for Freedom, Bombay 1988, s.986vd; B. Pattabhi Sitaramayya, İndian National Congress ( 1885-1935)I., Bombay 1946, s.189; N. Pandey, s.54.

29 Tilak 1890 yılında Kongre partisine katılmıştır. Kongre'nin yıllık toplantıları katılmıştır. Özellikle Kongre ile Müslim Lig arasındaki ılımlı tutumu özellikle Lucknov Paktı'nın 1916 yılında ilk, taraf arasında imzalanmasında etkisi olmuştur. Tilak’ın Kongre Partisindeki rolü hakkında geniş bilgi için bkz. S.S. Angadi, s. 98-129 vd.

30 Ganesh, Hindular tarafından tapılan fil başlı tanrıdır. Ganesh festivali hem çok eski hem de evrenseldir, tüm kastlar bir araya getirilmiş ve tüm Hindular için bir festival haline gelmiştir. Daha önce de yapılan bu festivalleri Tilak ulusal bir festival olarak popüler hale getirdi. Richard I. Cashman, s. 98vd.

31 Shivaji, Müslüman gücüne karşı savaşan ilk Hindu kahraman XVII. Yüzyılda Maratha eyaletinin kurucusu sayılır. Tilak, Maratha imparatorluğunun kurucusu Shivaji Maharaj’ın doğum yıl dönümünü kutlamak için Shri Shivaji Fon Komştesi’ni kurdu. Proje ayrıca Raigad Kalesi'ndeki Shivaji Maharaj'ın mezarının (Samadhi) yeniden inşasını finanse etme amacını da taşıyordu. Babu Aurobindo Ghose, s. 6881.

32 Christian Roy, Traditional Festivals a Multicultural Encyclopedia I, ABC-CLİ, California 2005, s.178-80; Biswamoy Pati, “Nationalist Politics and the Making of Bal Gangadhar Tilak", Gangadhar Tilak Popular Readings, (Ed. Biswamoy Pati), Primus Books, Delhi 2011, s.99; D.V. Tahmankar,s.59vd.

331905 yılında ülke çapında bir kutlama haline geldi. Zamanla her yıl düzenli yapılan bir festival geline geldi.

34 Sukeshi Kamra "Law and Radical Rhetoric in British India: The 1897 Trial of Bal Gangadhar Tilak", South Asia: Journal of South Asian Studies, vol 39/3, 2016, s. 546- 559 https://www.tandfonline. $\underline{\text { com/loi/csa20 }}$

S.S. Angadi, s. 3vd.; T.V.Parvate, s.168vd. 
da milliyetçi kahraman olarak görülmüştür. Swadeshi hareketi, Hindistan'da üretilen malların kullanımını hedeflemiştir. Bu harekette asıl amaç sadece İngiliz mallarını boykot etmek değil, aynı zamanda yerli girişimciliği teşvik etmekti. Hindistan'da yerli üretimi teşvik etmek istediği için gemi, kağıt üretimi sağlandığı gibi bu üretimler ahaliye de tanıtılmıştır. Yerli olarak üretilen mallar için ekonomik milliyetçilik ruhunu canlandırmak ve kültür yoluyla sosyal entegrasyon için çabalamak Tilak'ın stratejisinin özelliklerindendir. ${ }^{36}$ Ülkesi için büyük idealleri olan Tilak, Hindistan için şu tabirleri kullanmıştır. "Ben Hindistan'ı ana vatanım ve tanrıçam, Hindistan halkını ise benim akrabalarım olarak görüyorum ve onların politik ve sosyal alanlarda özgürleşmesi için sadık ve kararlı bir şekilde çalışmak da benim en yüksek dinim ve görevimdir. "'37

1905 yılında Hindistan ulusal harekâtına Hindistan tarihinde önemli bir dönüm noktası olan gelişme Bengal'in bölünmesi hadisesidir. ${ }^{38}$ Hindistan'1n o dönem yöneticisi Lord Curzon, eyalet konumundaki Bengal'in yönetimini kolaylaştırmak amacıyla 1905'te çıkarılan bir kanunla Doğu Bengal-Bihar-Orissa ve Batı Bengal-Asam olmak üzere iki ayrı eyalete ayırmıştır. ${ }^{39}$ Bölünme, Doğu Bengal'deki gayrimüslim nüfusuna nazaran Müslümanların sayısını $\operatorname{arttırdı.~}{ }^{40} \mathrm{Bu}$ ayrım Bengal Müslümanlarına ayrı bir eyalet vaat ederken, Müslüman ve gayrimüslim çatışmasını da alevlendirmiştir. Aynı zamanda bu bölünme hadisesi Hint alt kıtasında halkı siyasi açıdan müesseseleşmeye götüren en önemli etkenlerden biri olmuştur. Ahali, Hindistan Milli Kongresi ve Hindistan Müslümanları Birliği etrafında toplanmıştır. Gayrimüslim Hintliler bu bölünmeye şiddetle karşı çıkarken bunun önlenmesi için yoğun bir protesto faaliyetine girişmişlerdir. ${ }^{41} \mathrm{Bu}$ protesto faaliyetleri kısa sürede netice göstermiş ve Müslüman ve gayrimüslim birliğini bozan bu bölünme 1911yılında iptal edilmiştir.

36 Babu Aurobindo Ghose, s.374vd.

37 S.S. Angadi, s.71.

38 Günümüzde Bengal tabiri aslında geçmişte batılıların Hindistan coğrafyasını tanımlamada kullandığı bir terimdir. Bengal demek, Kalküta demek, Hindistan demektir. Günümüzün değişen haritasında ayrı bir yere koyduğumuz Bengal aslında ilk dönem İngilizleri için Hint coğrafyasının merkezidir. Kalküta sadece Bengal'in değil; tüm Hindistan'ın merkezi olma yolunda hızla gelişmişsir. İngilizler coğrafi olarak bu bölgeye o kadar çok uzaklardır ki merkezi yönetim ile Hint coğrafyasının yönetilmesine imkân yoktur. Bu nedenle Kalküta'ya atadıkları genel bir vali ile güçlerini kalıcı hale getirmişlerdir. Bombay ve Madras'a atanan valiler de Kalküta genel valisinin emrine girmiştir. Bengal İngilizler'in gözünde tarihi olarak her zaman kültürel bir öneme sahip olmuştur. İngilizlere göre Hint kültürünün temsil edildiği yer burasidir.

39 Geniş bilgi için bkz. Hikmet Bayur, s.469; Latif Ahmed Sherwani, Pakistan in the Making Documents and Readings, Karachi 1987, s.148; Maqbool Rehmat, Pakistan Studies History and Culture, Lahore 1999, s. 90 vd.; Pakistan Postası, S.10, 14Ağustos 1953, s.9.

$40 \mathrm{Bu}$ dönemde Bihar ve Orissa illeri birleşmiş olarak Bengal ilini teşkil etmekteydiler; Burada yaklaşı 78 milyonluk bir halk kitlesi yaşıyordu ve bu bakımdan yönetimi kolaylaştırmak için onun ikiye bölünmesi makul görülebilirdi. Bu il aynı zamanda sayıları bir düzine artan Kalküta Üniversitesinden çıkanların tahriklerine uğradığından onun yönetimi bu yüzden de ayrıca güçleşmişti. Amaç yalnız yönetimi kolaylaştırmak olsaydı tarihi Bengal ülkesini bir il yapmak ve ona katılmış olan Bihar ve Orissa'yı ondan ayırmak gerekirdi ve hiç olmazsa daha makul görülürdü. Lord Curzon'un başvurduğu tarzın bir sonucu da Doğu Bengal'de Müslümanlara, yani o sırada Kongre'in inkılap hareketlerine pek katılmayan bir unsura kesin bir çokluk sağlıyordu. Bkz Hikmet Bayur, s.469; Latif Ahmed Sherwani, s.148.

41 M. Penson, "The Bengal Administrative System 1786-1818”, The Cambridge History of India V; British India 1497-1858, (nşr.H.H.Dodwell), New Delhi 1958 ; Latif Ahmed Sherwani, s.140. 
Bengal'in doğu ve batı olarak bölünmesinin ardından Tilak, swadeshi hareketini teşvik ederken iki bunu yolla uygulanmıştır: ilki yabancı ürünlerin boykotu, ikincisi bu yabacı ürünleri kullanan Hintlilere sosyal boykot uygulanmasıdır. Yabancı ürünlerin boykotundan sonra oluşan boşluk yerli ürünlerle giderilmeye çalışılmıştır. İngiliz mallarını boykot etme çağrısı çok geçmeden bütün ülkeyi etkiledi. Ertesi yıl pasif direniş programını açıklayan Tilak bu programla İngiliz yönetiminin uyuşturucu etkisini ortadan kaldırmayı ve ahaliyi bağımsızlık uğruna katlanılacak zorluklara hazırlamaya çalışmıştır. Başlattığı bu boykot ve pasif direniş eylemleri sonradan Mahatma Gandhi tarafindan sürdürüldü. Tilak, Bengal'deki diğer önde gelen Hintli milliyetçilerden Bipin Chandra Pal ve Pencap'ta Lala Lajpat Rai tarafından da desteklenirken bu süreç kaynaklarda LalBal-Pal üçlü yönetimi olarak anılacaktır. ${ }^{42}$

$\mathrm{Bu}$ dönemde Maratha eyaletinde tuz vergisine karşı çok hoşnutsuzluk vardı. Bombay Kongresi tuz vergisiyle ilgili bir yasa tasarısını kabul etti. Maratha'da o günlerde tuz vergisine karşı büyük bir hoşnutsuzluk vardı. Tilak 1889'da Mahratta gazetesinde tuz vergisine karş1 görüş bildiren Rusden isimli bir İngiliz okurun mektubunu neşretti. Mektubun içeriği şu şekildeydi: "Bence hükümete bunun [tuz vergisi] aşağllık bir vergi olduğunu söylemenin vakti gelmiştir. Bu vergi en fakirlerin belini bükmektedir. Bu vergi en temel ihtiyaç maddelerine uygulanmaktadır. Ya fiyat ne olursa olsun tuzu alacaksin, ya da insanlara kendi tuzların üretmelerini ve vergi vermemelerini söyleyeceksin....Eğer bu insanlara karşı dava açılırsa onların savunmaları için para toplanmalıdır ki 100 milyon Hindistan vatandaşı onları yönetenlerin kendi yaşadıkları sıkıntıları duymaları için seslerini yükseltmeleri gerektiğini akıllarına soksun." ${ }^{43} \mathrm{Bu}$ mektup İngiliz yönetimini huzursuz etmişti. Aslında, bu mektup Gandhi'nin tuz Satyagraha'nın habercisiydi. Tilak tarafından başlatılan boykot edilme pasif direniş daha sonra Gandhi'nin temel ilkesi olmuştur. Gandhi şiddetsiz siyasal sistem ve eylemleri sayesinde emperyalist egemenlik arzusu ile insanlık dışı uygulamalara başvurmaktan çekinmeyen İngilizlerin bu arzularını yavaş yavaş zayıflatmış ve nihayetinde ülkesinde süregelen İngiliz sömürgeciliğini yıkmayı başarmıştır. Böylece adaletsizliğe başkaldırının şiddet ve kanla değil de fikirsel ve barışçıl eylemlerle zafer kazanacağına tüm dünya şahit olmuştur. ${ }^{44}$

Nitekim bahsi gecen mektubu ve sonrasında iki gencin Kalküta'nın İngiliz temsilcisini öldürmeye yönelik eylemlerini destekleyen ve bu eylemleri swaraj yani öz yönetim olarak değerlendiren yazısı, Tilak'ın isyana kışkırtma ve terör suçundan 1908 yılından 1914 yılına kadar Mandalay hapishanesine gönderilmesine neden oldu. ${ }^{45}$ Hapishanedeyken Hint milliyetçiliğine dair fikirlerini daha da geliştirdiği gibi okumaya ve yazmaya devam etti. Bu süreçte iki eseri Artic Home of the Vedas ve Gita Rahasya'yı kaleme aldı. Bu eserler dini ve felsefi yönlü çalışmaları ihtiva etmekte olup kitapların satışı ile elde edilen gelirler özgürlük mücadelesine bağışlanmıştır. ${ }^{46}$

42 Vishnuchandra Sharma, Tilak the Torch Bearer of Swaraj, Puplications Division, New Delhi 2018, s.2.

43 Vishnuchandra Sharma, s.17. D.V. Tahmankar, s. 104.

44 Geniş bilgi için bkz. The Collected Works of Mahatma Gandhi XIX.

451908 yılında Bengalli iki genç Muzzafarpur'da araç üzerinden bir bomba atar maksatları Kalküta’nın İngiliz temsilcisini öldürmektir. Ama onun yerine o araçta yolculuk yapan iki kadın ölür. Eylemi yapan gençler yakalanınca biri intihar eder diğeri ise idam edilir. Tilak Kesari gazetesinde bu iki genci savunur ve bunu bir öz yönetim olarak değerlendirir. Bunun üzerine Tilak 1908 yılında isyana kışkırtma ve terör sucundan hapse atıldı. Bin rupi de para cezasına çarptırılır. Vishnuchandra Sharma, s.17-18.

46 Sanjay Seth "The critique of renunciation: Bal Gangadhar Tilak's Hindu nationalism", Postcolonial Studies, IX/2, 2006,s.137-150. https://doi.org/10.1080/13688790600657819; Robert W. Stevenson, 
Tilak, 1914 yılında hapishaneden çıkmışsa da sonraki günlerinde şeker hastalığı gibi bazı sağlık sorunları ile uğraşmıştır. ${ }^{47}$ Yine de davasından ödün vermeyen Tilak, 1916 yılında Hint Ulusal kongresine tekrar katılarak Kongre Partisi için bir yol gösterici olduğu gibi Morley Minto, Lucknov gibi Hint alt kıtasının siyasi hayatını etkileyen kararların alınmasında da etkisi olmuştur. ${ }^{48}$ Tilak, kendi kendini yönetme hareketi olan swaraja katılmak için çiftçilerden ve yerel halktan destek bulmaya çalışırken köy köy dolaşmıştır. Bu gezilerinde her dinin bulunduğu özgür Hindistan için federal bir sistemin gerekli olduğunu dile getirmekteydi. Bu manada o aynı zamanda Hintçenin Hindistan'ın ulusal dili olarak kabul edilmesini ön gören ilk Kongre lideriydi.

Siyasi hayatına Maratha propagandacısı olarak başlayan Tilak, zamanla Hint milliyetçisi olarak ön plana çıktı. Özellikle Bengal'in bölünmesinden sonra kendisine yöneltilen: Özgür bir Hindistan için Maratha gibi bir hükümet mi istiyorsun? sorusuna Maratha, XVII. ve XVIII. yüzyıl için bu görüş geçerliydi, artık XX. yüzyılda bu görüşün modasının geçtiğini, her din ve ırkın bulunduğu özgür Hindistan için gerçek bir federal sistem istediğini söyledi. Hindistan'ın özgürlüğünü ancak böyle bir hükümetin koruyabileceğini de sözlerine ekledi. Swarajın ilk ve en güçlü savunucularından Tilak, ne yazık ki hayalini kurmuş olduğu özgür Hindistan'ın 1947 yılında bağımsızlığını göremeden 1 Ağustos 1920'de Mumbai'de 64 yaşında hayatını kaybetmişse de ${ }^{49}$ “Lokamanya Tilak” olarak Hint tarihindeki ölümsüzlügünü hala devam ettirmektedir.

\section{Sonuç}

Modern Hindistan'ın adeta mimarı olan Tilak, boyun eğmez iradesi, vatanseverliği, fedakârlığı, cesareti, bağımsız karakteri ile ön plana çıkmıştır. XVIII. yüzyılın son çeyreğinden itibaren Hint alt kıtasına tamamen hâkim olan İngiliz yönetimine karşı en etkili mücadele yolu olan swarajın yani ulusal egemenliğin ilk ve en güçlü savunucularından biri olarak Hint tarihine “Lokamanya Tilak" olarak adını yazdırmıştır.

"Swaraj benim doğuştan hakkımdır ve ben de ona sahip olacă̆ım." sloganı ile hareket eden Tilak, aynı zamanda Hindistan siyasi tarihinin şekillenmesinde önemli rol alan Kongre Partisi'nin önde gelen temsilcilerindendir. Partinin programının belirlenmesinde etkin rol oynayan Tilak, ayrıca Hintçenin Hindistan'1n ulusal dili olarak kabul edilmesini ön gören ilk Kongre lideriydi.

Kesari ve Mahratta adlı haftalık iki gazete aracılığıyla halkta siyasi bilinç uyandırmaya çalışmıştır. Bu faaliyetleriyle İngiliz hükümeti tarafından tehlikeli görülmüş üç defa hapse atılmıştır. Nitekim Tilak’ı Hint alt kıtasında ölümsüz kılan faaliyetlerinden biri de milliyetçilik hareketlerinin yaygınlaştırmak için düzenlemiş olduğu festivallerdir. 1893 yılında Ganesh ve 1895 yılında Shivaji olmak üzere iki önemli festival düzenledi. Binlerce kişi katılıldığı bu festivaller milliyetçi hareketin sembolü olarak Tilak tarafından başlatıldıktan sonra her yıl düzenli olarak yapılmaktadır. Bu festivaller aynı zamanda tüm kastlardan ve topluluklardan sıradan insanlar için

"Tilak and the Bhagavadgita's Doctrine of Karmayoga", Modern Indian Interpreters of the Bhagavad Gita (Ed. Robert R. Minor), State University of the New York Press, Albany 1986.

$47 \quad$ S.S. Angadi, s. 23.; T.V.Parvate, s.260.

48 1916'da Muhammed Ali Cinnah'la Hindu-Müslüman birliğini sağlayan Lucknow Paktı'nı imzalamıştır. Geniş bilgi için bkz. S.S. Angadi, s. 25, T.V.Parvate, s.223.

49 Dhananjay Keer, Lokamanya Tilak Father of our Freedom Struggle, Forthcoming Books, Bombay 1959. 
bir buluşma yeri olarak hizmet etmektedir. Söz konusu festivaller zamanla dini ve sosyal açıdan işlevsel bir hal alırken kültürel programlar ve milliyetçi konuşmalarla insanlara vatanseverlik duygusu aşılanmıştır.

Tilak, Swaraj'ın asıl hedefine ulaşmak için Swađeshi, boykot, ulusal eğitim ve pasif direniş tekniklerini uygularken yabancı mallarını boykot ederek yerli girişimciliği teşvik etmiştir. Neticede Hintlilerin yabancı yönetimle işbirliği yapmalarından vazgeçmesi gerektiğini ileri süren ilk önderlerinden biri olan Tilak'ın bu ideallerini gerçekleştirmede hiçbir zaman şiddeti özendirmediği de dikkat çekmedir. Tilak'ın başlatmış olduğu bu hareket, daha sonra Hint milliyetçiliğinin babası olan Gandhi'nin temel ilkesi olmuştur. Gandhi şiddetsiz siyasal sistem ve eylemleri sayesinde emperyalist egemenlik arzusu ile insanlık dışı uygulamalara başvurmaktan çekinmeyen İngilizlerin bu arzularını yavaş yavaş zayıflatmış ve nihayetinde ülkesinde süregelen İngiliz sömürgeciliğini yıkmayı başarmıştır. Neticede Tilak tarafından başlatılan Swadeshi hareketi, 1947'de bu hedefe ulaşılana kadar yalnızca bağımsızlık hareketinin değil aynı zamanda Hindistan Hükümeti’nin de bir parçası olmuştur.

\section{Kaynakça}

Agnihotri, V. K., Indian History, New Delhi 2010.

Ahmed, A., Hindistan'da İslam Kültürü Çalışmaları, (nşr., L. Boyacı), İstanbul 1995.

Anbarl1, S.., "Bir Pasif Direnme Modeli Olarak Sivil İtaatsizlik", Cumhuriyet

Üniversitesi, İktisadi ve İdari Bilimler Fakültesi Dergisi II/1, 2001, s.319-328.

Angadi, S.S., Bal Gangadhar Tilak: A Study of His Role in the Indian Nationalist Movement, Karnatak University, Dharwad 1992.

Baptısta, J., About Lokamanya Tilak, Vavilla Press, Madras 1922.

Bayur, Y.H., Hindistan Tarihi III, Ankara 1987.

Bhosale, B.G., Indıan Natıonalısm: Gandhı vis-a-vis Tilak and Savarkar, The Indian Journal of Political Science LXX/2, Indian Political Science Association, 2009

Briggs, H.G., The Nizam His History and Relations with the British Government III, Delhi 1985.

Cashman, R.I., The Myth od the Lokamanya Tilak and Mass Politics in Maharashtra, University of Calfornia Press, London 1975.

Chandra, B., India's Struggle for İndependence, New Delhi 1989.

Desai, A. R., Social Bankround of India Nationalism, Bombay 1966.

Dutt, R., The Economic History of India in the Victorian Age (from the Accession of Queen Victoria in 1837 to the Commencement of the Twentieth Century), London 1958.

Edward, S.M., "The Final Struggle with the Marathas, 1784-1818", The Cambridge

History of India V; British India 1497-1858, (nşr.H.H. Dodwell), New Delhi 1958, s.379.

Frazer, R.W., A Story of the Nations British India, London 1918. 
George, K.H., British Administration During The Revolt of 1857, New Delhi 1985.

Ghose,B. A., Bal Gangadhar Tilak His Writings and Speeches, Ganesh, Madras 1922.

Habermas, J., Sivil İtaatsizlik, (nşr. Hayrettin Ökçesiz), Afa Yayınları, İstanbul 1995.

Hopkins, E.W., "The Growth of Law and Legal Instituons", The Cambridge History of India I, (nşr.E.J. Rapson), Delhi 1955. (s.259-270)

Hunter, W.W., The Indian Musalmans, London 1871.

Innes, A.D., A Short History of The British in India, New Delhi 1985.

Iyer, R. N., The Moral and Political thought of Mahatma Gandhi, New Delhi 2003.

Kamra, S., "Law and Radical Rhetoric in British India: The 1897 Trial of Bal Gangadhar Tilak", South Asia: Journal of South Asian Studies, 39/3, 2016, s. 546- $559 \quad$ https://www. tandfonline.com/loi/csa20

Karpat, K. H., İslam’ın Siyasallaşması, ( nşr. Şiar Yalçın), İstanbul 2013.

Keer, D., Lokamanya Tilak Father of our Freedom Struggle, Forthcoming Books, Bombay 1959.

Khan, A.Z., "Socio-Economic Reforms", Road to Pakistan, (nşr. H.Msaid-S.MujahidA.Zahid Khan), Karachi 1990.

Kincaid, D., British Social Life in India 1608-1937, London 1939.

Kulke, H. - Rothermund, D., Hindistan Tarihi, ( nşr. M. Günay), İstanbul 2001.

Lovett, H. V ., "The Growth of Educational Policy, 1858-1918”, The Cambridge History of India VI, (nşr. H. H. Dodwell), Delhi1958.

Majumdar, R.C., British Paramountcy and İndian Renaissance I., Bombay 1988.

Majumdar, R.C., Struggle for Freedom, Bombay 1988.

Natesan, G. A., The National Congress, Madras 1917.

Owen, S. J., The Fall of the Mogul Empire, London 1912.

Padmasha, Indian National Congress and the Muslims (1928-1947), New Delhi 1980.

Pakistan Postası, S.10, 14Ağustos 1953.

Pandey, N., The İndian Nationalist Movement 1885-1947, New Delhi 1979.

Parvate, T.V., Bal Gangadhar Tilak a Narrative and İnterpretative Review of his Life, Career and Contemporary Events, Navajivan Publishing House, Ahmedabad 1958,

Pati, B., "Nationalist Politics and the Making of Bal Gangadhar Tilak", Gangadhar Tilak Popular Readings, (Ed. Biswamoy Pati), Primus Books, Delhi 2011, (s.99-110)

Patil, A.," Public Opinion in Colonial India: The Kesari and the Kolhapur Affair, 18811883", Proceedings of the Indian History Congress LXVII, 2006, (s.711- 724)https://www.jstor. org/stable/44147990 01.12.2020

Penson, M., "The Bengal Administrative System 1786-1818”, The Cambridge History of 
India V; British India 1497-1858, (nşr.H.H.Dodwell), New Delhi 1958.

Qidwa, İ., "The Establishment of the British Raj”, $\quad$ Road to Pakistan, (nşr. H.Msaid-S.Mujahid-A.Zahid Khan), Karachi 1990.

Rawlinson, H.G., A. Concise History of the Indian People, Oxford 1958.

Rehmat, M., Pakistan Studies History and Culture, Lahore 1999.

Roy,C., Traditional Festivals a Multicultural Encyclopedia I, ABC-CLİO, California 2005.

Samarth, A., Shivaji and the Indian National Movement, Somayya Publications Pvt., Bombay 1975.

Saxena, N.C., Muslims and the India National Congress, Delhi 1955.

Selected Documents of Lokamanya Bal Gangadhar Tilak 1880-1920 I-IV., (Ed.Ravindar Kumar ), Anmol Publications, 1992.

Seth, S., "The critique of renunciation: Bal Gangadhar Tilak's Hindu nationalism”, Postcolonial Studies,IX/2,2006,s.137-150https://doi.org/10.1080/13688790600657819

Sharma, J. N., The Political Thought of Lokamanya Bal Gangadhar Tilak XXIV,Concept Publishing Company, New Dehli 2009.

Sharma, V., Tilak the Torch Bearer of Swaraj, Puplications Division, New Delhi 2018.

Sherwani, L. A., Pakistan in the Making Documents and Readings, Karachi 1987.

Sitaramayya, B. P., The History of the Indian National Congress (1885-1935) I., Bombay 1946.

Sitaramayya, B. P., Gandhi and Gandhizm I., Allahabad 1943.

Stevenson, R. W., "Tilak and the Bhagavadgita's Doctrine of Karmayoga”, Modern Indian Interpreters of the Bhagavad Gita (Ed. Robert R. Minor), State University of the New York Press, Albany 1986.

Tahmankar, D.V., Lokamanya Tilak, London 1956.

The Collected Works of Mahatma Gandhi-Volume 18, 19.

Thoreau, H. D., Sivil ve İtaatsiz, (nşr., Emine Ebru),Kafekültür Yayıncılık, İstanbul 2014.

Toynbee, A.J, Dünya ve Garp, (nşr. E. Bilgiç), İstanbul 1952.

Vural, S., Hindistan'da İngiliz Yönetimi, Malatya 2006.

Woodruff, P., The Men Who Ruled India I, New York 1964. 